nephron

Practice

\title{
The Fault Is Not in Our Stars but May Be in Our Embryos: Glomerular Number in Low Birth Weight Babies
}

\author{
David G. Warnock \\ Department of Medicine, University of Alabama at Birmingham, Birmingham, AL, USA
}

The issue of long-term outcomes for infants with low birth weight (LBW) has gained a strong foothold in the areas of hypertension and chronic kidney disease (CKD). Based on the pioneering work of David Barker $[1,2]$ on the fetal origins of adult disease, there is now general acceptance of the thesis that LBW is a robust predictor for both fetal and adult well-being. An important extension and focus in the renal community have been on the notion of "nephron endowment," referring to the number of functional units, i.e., "nephrons," and the appreciation that there may be compromised optimal development of functional units with preterm delivery and/or LBW [3-5].

The contributions of limited nephron endowment and low fetal birth weight are emerging as important factors in global health initiatives [6]. These issues were brought to focus in a recent international multidisciplinary conference entitled "The fault is not in our stars but may be in our embryos: glomerular number in low birth weight babies" and held at the Aldo and Cele Daccò Clinical Research Center for Rare Diseases in Ranica just outside Bergamo (Italy) in April 2016 (http://www.marionegri.it/ media/news/PROGRAMMA_2_Aprile2016.pdf). This conference was organized under the aegis of the Italian Society of Nephrology, with invaluable and substantial support from the Fondazione Internazionale Menarini and additional help from the Chiesi Foundation under the auspices of the Istituto di Ricerche Farmacologiche Mario Negri. The workshop was a unique opportunity to discuss issues related to fetal programming of CKD, to

\section{KARGER}

(c) 2017 S. Karger AG, Basel

E-Mail karger@karger.com

www.karger.com/nef highlight the relevance of this problem to the global health burden of chronic disease, and suggest possible practical solutions for the future. The workshop was intended to raise awareness about the role of developmental programming in the risk for developing subsequent renal disease, and to support implementation of locally adapted preemptive strategies that will have important long-term benefits in terms of future health and cost saving worldwide.

The consensus statement for this important conference is presented in this issue of Nephron [7]. The participants in the workshop and consensus statement were a group of experts in obstetrics, neonatology, and nephrology who focused on the associations between fetal and childhood development and increased risk of adult disease, including hypertension, diabetes, and CKD. LBW and prematurity, the most consistent clinical surrogate for a low nephron number, are associated with an increased risk of hypertension, proteinuria, and kidney disease in later life. This relationship is amplified with the use of nephrotoxic drugs that may further reduce nephron number soon after birth, as well as by rapid catch-up growth or overfeeding during infancy or childhood, especially in the setting of previous maternal and fetal malnutrition/undernutrition, which may predispose to obesity and type 2 diabetes in later life. The consensus statement addresses the broad spectrum of developmental programming of kidney disease from preconception to aging. 
1 Barker DJ: The developmental origins of wellbeing. Philos Trans R Soc Lond B Biol Sci 2004;359:1359-1366.

-2 Barker DJ: Sir Richard Doll Lecture. Developmental origins of chronic disease. Public Health 2012;126:185-189.

-3 Brenner BM, Garcia DL, Anderson S: Glomeruli and blood pressure. Less of one, more the other? Am J Hypertens 1988;1(4 pt 1): 335-347.

4 Mackenzie HS, Brenner BM: Fewer nephrons at birth: a missing link in the etiology of essential hypertension? Am J Kidney Dis 1995; 26:91-98.
5 Luyckx VA, Brenner BM: The clinical importance of nephron mass. J Am Soc Nephrol 2010;21:898-910.

-6 Luyckx VA, Brenner BM: Birth weight, malnutrition and kidney-associated outcomes - a global concern. Nat Rev Nephrol 2015;11: 135-149.

The Low Birth Weight and Nephron Number Working Group: The impact of kidney development on the life course: a consensus document for action. Nephron 2017;136: 3-49. 